\title{
Physical and Emotional Burden of Rheumatoid Arthritis: Data from RA Matters, a Web-Based Survey of Patients and Healthcare Professionals
}

\author{
Rieke Alten - Mart van de Laar - Francesco De Leonardis • \\ Nicole Tietz · Mariana Guerreiro · Ronald van Vollenhoven
}

Received: August 8, 2019 / Published online: October 28, 2019

(C) The Author(s) 2019

\begin{abstract}
Introduction: This survey assessed the impact of rheumatoid arthritis (RA) on the lives of patients based on the perceptions of both patients and healthcare professionals (HCPs).

Methods: This is a cross-sectional survey of patients with RA. Data were collected from patients and HCPs who manage RA using a structured, closed-ended questionnaire in their local language. Respondents for the survey were recruited from survey panels of verified unique responses. The survey focused on the impact of
\end{abstract}

Enhanced Digital Features To view enhanced digital features for this article go to https://doi.org/10.6084/ m9.figshare.9976151.

Electronic Supplementary Material The online version of this article (https://doi.org/10.1007/s40744019-00179-2) contains supplementary material, which is available to authorized users.

R. Alten ( $\square)$

Schlosspark-Klinik University Medicine, Berlin, Germany

e-mail: rieke.alten@schlosspark-klinik.de

M. van de Laar

Arthritis Centre Twente, Medisch Spectrum Twente, Enschede, The Netherlands

F. De Leonardis · N. Tietz · M. Guerreiro

Eli Lilly and Company, Indianapolis, IN, USA

R. van Vollenhoven

Amsterdam University Medical Centers,

Amsterdam, The Netherlands disease on four domains: daily activities, relationships, work and aspirations.

Results: Overall, 1231 adult patients with RA and 270 rheumatologists or other HCPs were surveyed between November 2016 and February 2017. Almost one in three patients believed that the impact of RA is not well understood by people without the disease. Fifty-eight percent [95\% confidence interval (CI) 55-61\%] of patients felt frustrated when they were unable to undertake or complete daily activities because of their disease. Fifty-seven percent (95\% CI 54-60\%) of patients wished to be able to accept their life with RA. Forty-three percent (95\% CI $40-46 \%$ ) of patients hoped that the physical impact of RA will be better understood in future. Forty percent (95\% CI 37-43\%) of patients were forced to take long-term leave/ retirement or experienced slow career progression since being diagnosed with RA. Twentythree percent (95\% CI 21-25\%) of patients had difficulties in taking care of personal grooming, whereas $8 \%$ (95\% CI 6-10\%) of patients reported that RA ruined their life. Similar responses were observed among HCPs.

Conclusion: Patients and HCPs feel that the physical and emotional impact of RA is not well understood by people without the disease. In RA treatment decisions, patients' personal goals and patient-reported outcomes should be taken into consideration along with clinical targets.

Funding: Eli Lilly and Company (Indianapolis, IN, USA). 
Keywords: Burden of illness; HCPs; Patients; Patient goals; Quality of life; Questionnaire; RA Matters; Rheumatoid arthritis; Survey

\section{Key Summary Points}

\section{Why carry out this study?}

Despite major advances in the management of the disease, not much is known about the impact of rheumatoid arthritis (RA) on patients' private and social lives.

The objectives of this survey were

To understand the impact of RA on the lives of patients based on the perceptions of both patients and healthcare professionals (HCPs)

To characterize the effect of the disease on relationships, work and daily activities

To describe potential differences between the perceptions of patients and those of HCPs regarding the effects of RA

\section{What was learned from the study?}

Both patients and HCPs felt that the physical and emotional impact of RA is not well understood by people without the disease. Pain, fatigue and physical function remain primary barriers for patients to live a normal life.

Despite major advancements in the treatment of RA, the disease continues to significantly affect many aspects of patients' lives, including relationships, career progression, daily activities and ability to work.

\section{INTRODUCTION}

Rheumatoid arthritis (RA) is a chronic systemic inflammatory disorder that has a well- documented negative impact on patients' health-related quality of life (QOL) $[1,2]$.

RA affects approximately 2.5 million patients in Europe and Canada, and 20-50 new cases are diagnosed annually per 100,000 population [3-6]. RA can lead to permanent disability and is associated with major losses in workforce participation [7].

Although conventional synthetic diseasemodifying antirheumatic drugs (DMARDs) and biologic DMARDs have revolutionised the management of RA, the physical and psychological burden on patients remains relevant $[8,9]$. Most surveys conducted among patients with RA have highlighted the burden of illness, QOL, mental health, emotional well-being, employment and patient-physician interactions.

The objective of this survey was to understand the impact of RA on the lives of patients based on the perceptions of both patients and healthcare professionals (HCPs), in particular the effect of the disease on interpersonal relationships, ability to work, career progression, ability to stay active and aspirations for their future. The survey also aimed to assess potential differences between the perceptions of patients and HCPs regarding the effects of RA.

\section{METHODS}

\section{Design and Survey Flow}

KRC Research, a global public opinion research consultancy, was commissioned by Eli Lilly and Company to conduct an online survey of patients with a self-reported diagnosis of RA and rheumatologists or HCPs (including nurses, pharmacists and other medical specialties) who manage RA, between November 2016 and February 2017 from selected European countries and Canada (Table 1) [10]. Patients and HCPs were not required to be directly paired. The survey used closed-ended questions with nominal and interval scales and was administered online via social media, RAMatters.eu and RAMatters.ca websites.

Respondents were screened using a screener questionnaire and, to qualify, had to be 
Table 1 Respondent distribution by country

\begin{tabular}{lccc}
\hline Country & Patients $(n)$ & HCPs $(n)$ & Total $(n)$ \\
\hline Canada & 279 & 20 & 299 \\
France & 166 & 65 & 231 \\
Germany & 302 & 35 & 337 \\
Italy & 185 & 70 & 255 \\
Netherlands & 0 & 20 & 20 \\
Sweden & 0 & 19 & 19 \\
UK & 299 & 41 & 340 \\
Total & 1231 & 270 & 1501 \\
\hline
\end{tabular}

All respondents are residents of their respective countries

diagnosed with RA by a rheumatologist or be an HCP with experience in the management of RA. The survey focused on the impact of disease on four domains: daily activities, relationships, work and aspirations. The domains were identified on the basis of a previous survey among patients in Europe (see S1 in the electronic supplementary material for details). Data were collected utilising a mixed method sampling plan, which included voluntary, previously identified respondents from professionally managed survey respondent panels, as well as respondents recruited through an open online survey. To increase the reproducibility of the data, this report focuses on the results generated from the panel respondents only. Patients and HCPs were provided with nearly identical surveys (Fig. 1).

\section{Compliance with Ethics Guidelines}

The research was carried out in compliance with national laws protecting respondents' personal data and with the European Society for Opinion and Market Research, the European Pharmaceutical Marketing Research Association and the British Healthcare Business Intelligence Association.

For this survey, ethics committee approval was not required, in line with the standards and guidelines set by Market Research Industry
Associations. At the beginning of the survey, respondents were asked to explicitly give consent to participate in the survey. No clinical data were collected in this survey.

\section{Statistical Methods}

Descriptive analyses were conducted to describe the patient sample with regard to their demographic responses. Categorical data were summarised using both frequency and percentages of patients. Percentages were calculated using the number of observations with non-missing values in the denominator (unless otherwise noted). Results are presented with their Wald 95\% confidence intervals (CIs), based on the normal approximation.

\section{RESULTS}

\section{Demographics}

On the basis of the analysis of the panel data, 1231 patient respondents from Canada, France, Germany and the UK, and 270 rheumatologist or HCP respondents from the Canada, France, Germany, Italy, the Netherlands, Sweden and the UK were enrolled in this survey. The highest number of HCPs who responded was from Italy while the highest number of patients who responded was from Germany and the UK (Table 1). Patient and HCP demographics were similar in those countries with both respondents (Tables 2, 3). A majority of patients overall and in each country were female.

\section{Survey Results}

Survey results are reported in detail in Table 4 .

\section{Effect of RA on Relationships}

Of the 1231 patients who participated, 35\% (95\% CI 32-38\%) and 39\% (95\% CI 36-42\%) of patients reported that people without RA understand the emotional and physical impact of the disease, respectively. Twenty-one percent (95\% CI 17-25\%) of patients who felt their condition is understood reported that their 


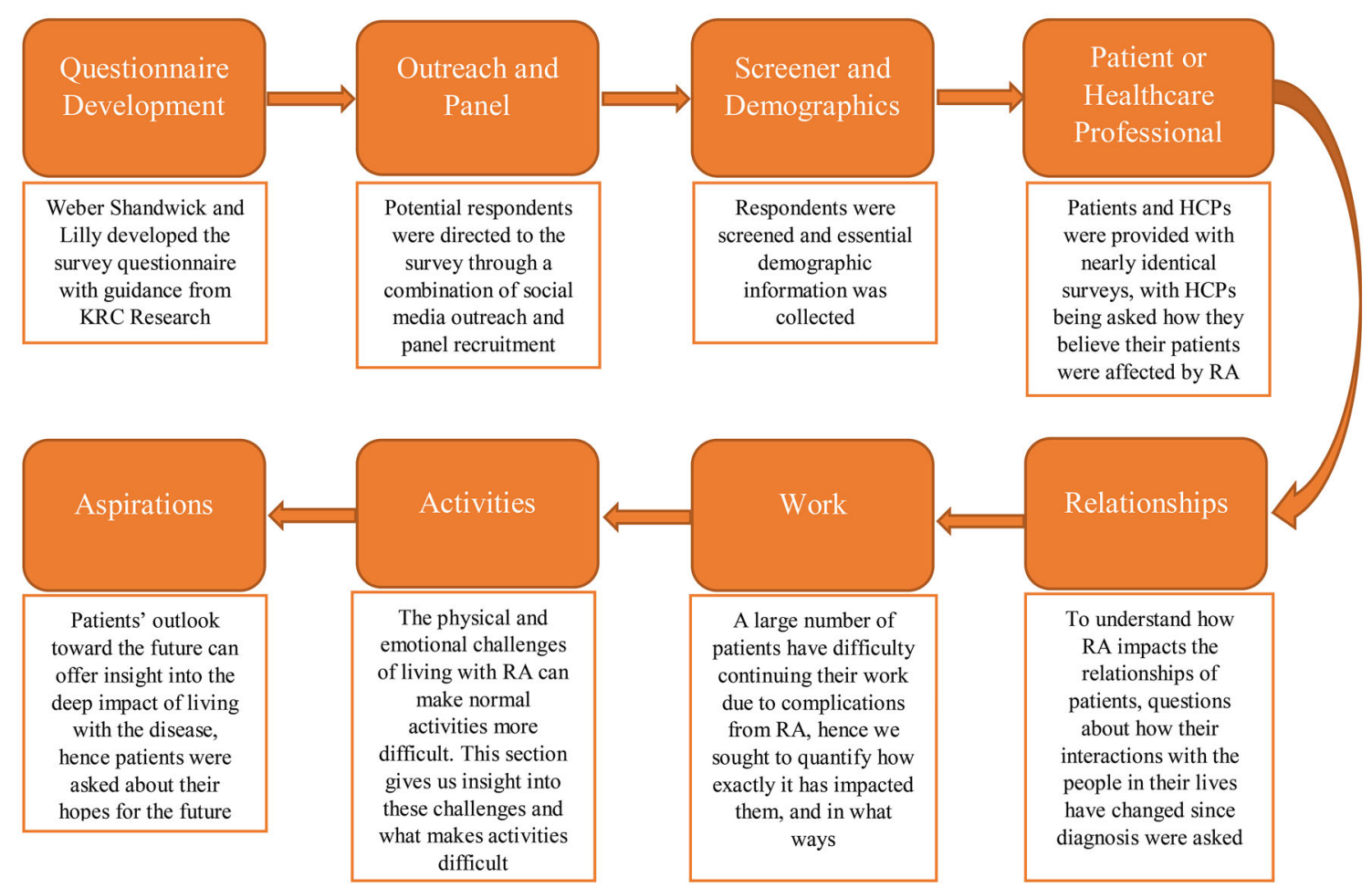

Fig. 1 Survey flow

relationships with their spouse or partner have been negatively impacted.

Among 1231 patients, 38\% (95\% CI 35-41\%) more patients in a relationship or with children felt that the emotional impact of RA is understood by others as compared with 30\% (95\% CI $27-33 \%)$ of single, divorced or widowed patients, and $28 \%$ (95\% CI $25-31 \%)$ of patients without children $(p<0.05)$, respectively. Fortyeight (95\% CI $45-51 \%$ ) percentage of patients reported the strongest negative impact on sex life and intimacy and $44 \%$ (95\% CI $41-47 \%$ ) of patients reported inclusion in family and social events to be negatively affected. HCP responses are reported in Table 4 .

\section{Effect of RA on Work}

Forty percent (95\% CI 37-43\%) of patients reported long-term leave/retirement or hampered career progression since being diagnosed with RA. Eighteen percent (95\% CI 16-20\%) of patients reported to have been forced to leave their job or retire because of RA, while another
23\% (95\% CI 21-25\%) have experienced a slow career progression.

More than one-third of patients reported not receiving adequate physical (31\%; 95\% CI $28-34 \%$ ) or emotional (36\%; 95\% CI 33-39\%) accommodation from their colleagues.

Patients cited difficulty using hands (44\%; 95\% CI $41-47 \%$ ), inability to work due to pain (43\%; 95\% CI 40-46\%) and unpredictability about how they will feel (34\%; 95\% CI 31-37\%) as the biggest barriers to carrying out their work.

Responses from the HCPs further emphasised these findings. Up to $62 \%$ of HCPs reported that their patients' career progression has slowed down since they were diagnosed with RA.

\section{Effect of RA on Activities}

Fifty-eight percent (95\% CI 55-61\%) of patients reported exercising to be difficult. Furthermore, almost one quarter (23\%; 95\% CI 21-25\%) found personal grooming to be difficult.

Physical difficulties such as pain $(61 \% ; 95 \%$ CI 58-64\%), aching/stiff joints (52\%; 95\% CI 
Table 2 Patient demographics

\begin{tabular}{|c|c|c|c|c|c|c|}
\hline & Total & Canada & France & Germany & Italy & UK \\
\hline \multicolumn{7}{|l|}{ Age, years (\%) } \\
\hline$<40$ & 22 & 22 & 28 & 21 & 31 & 15 \\
\hline $40-59$ & 48 & 47 & 45 & 48 & 55 & 47 \\
\hline $60+$ & 30 & 31 & 28 & 31 & 14 & 38 \\
\hline \multicolumn{7}{|l|}{ Gender (\%) } \\
\hline Male & 42 & 37 & 43 & 41 & 46 & 46 \\
\hline Female & 58 & 63 & 57 & 59 & 54 & 54 \\
\hline \multicolumn{7}{|l|}{ Marital status (\%) } \\
\hline In a relationship, not married & 15 & 18 & 15 & 15 & 13 & 14 \\
\hline Married & 54 & 48 & 52 & 56 & 66 & 52 \\
\hline Single, never married & 15 & 17 & 20 & 11 & 15 & 15 \\
\hline Divorced & 8 & 9 & 8 & 11 & 2 & 10 \\
\hline Separated & 3 & 5 & 2 & 2 & - & 3 \\
\hline Widowed & 4 & 4 & 2 & 5 & 4 & 5 \\
\hline \multicolumn{7}{|l|}{ Has children (\%) } \\
\hline Yes & 74 & 74 & 77 & 73 & 78 & 72 \\
\hline No & 26 & 26 & 23 & 27 & 22 & 28 \\
\hline \multicolumn{7}{|l|}{ Employment status (\%) } \\
\hline Working full-time & 42 & 39 & 46 & 40 & 57 & 35 \\
\hline Working part-time & 16 & 15 & 13 & 22 & 13 & 14 \\
\hline Volunteer & 1 & 1 & 1 & 1 & 2 & 2 \\
\hline Student & 1 & 1 & 1 & 1 & 2 & - \\
\hline Homemaker & 9 & 9 & 11 & 7 & 8 & 11 \\
\hline Unemployed & 8 & 10 & 6 & 5 & 10 & 9 \\
\hline Retired & 23 & 25 & 22 & 24 & 9 & 29 \\
\hline \multicolumn{7}{|l|}{ Are you/do you? (\%) } \\
\hline Associated with an advocacy or support group of patients living with RA (e.g. NRAS) & 7 & 5 & 11 & 7 & 12 & 6 \\
\hline $\begin{array}{l}\text { Online communities or forums for patients living with RA (e.g. NRAS where you chat and } \\
\text { consult with other patients with RA over the internet) }\end{array}$ & 10 & 5 & 11 & 10 & 12 & 12 \\
\hline Both of the above & 5 & 6 & 4 & 2 & 7 & 5 \\
\hline Neither of the above & 78 & 84 & 74 & 81 & 69 & 78 \\
\hline
\end{tabular}

NRAS National Rheumatoid Arthritis Society, $R A$ rheumatoid arthritis

49-55\%) and fatigue (37\%; 95\% CI 34-40\%) were primary barriers to activities for patients with RA. Fifty-eight percent (95\% CI 55-61\%) of patients felt "frustrated", followed by "feeling anxious" (32\%; 95\% CI 29-35\%) or "like a failure" (25\%; 95\% CI 23-27\%), when they were unable to undertake or complete activities because of the disease. Patients aged 40 years or above were more likely to report feelings of frustration than the younger ones. HCP responses are reported in Table 4.

\section{Effect of RA on Aspirations}

Fifty-seven percent (95\% CI 54-60\%) of patients reported that they would like to be able to accept their life with RA and to cope with it in the future. Patients who felt that the emotional impact of their disease was better understood showed greater acceptance of the disease $[17 \%$ 
Table 3 Healthcare professional demographics

\begin{tabular}{lllllllll}
\hline & Total & Canada & France & Germany & Italy & Netherlands & Sweden & UK \\
\hline Gender (\%) & & & & & & & & \\
Male & 61 & 40 & 46 & 86 & 71 & 50 & 53 & 63 \\
Female & 39 & 60 & 54 & 14 & 29 & 50 & 47 & 37 \\
\hline
\end{tabular}

vs $10 \%$, respectively $(95 \%$ CI $13-21 \%$ vs 7-13\%)]. Eight percent (95\% CI 6-10\%) of respondents reported that RA has ruined their life.

Forty-three percent (95\% CI 40-46\%) of the patients wished for a better understanding of the physical impact of RA on their lives from others. Of those aged 60 years or above, 37\% (95\% CI 32-42\%) wished for non-patients to understand that they are trying their hardest to manage the disease.

More than three quarters placed most importance on being able to complete everyday activities (76\%; 95\% CI 74-78\%). Being able to take a vacation was considered as an important activity by $70 \%$ of the patients. HCP responses are reported in Table 4.

\section{DISCUSSION}

Thanks to the major advances introduced in the past two decades, RA treatment outcomes have markedly improved over time. Despite this, it has been reported that the overall patient perception of well-being has decreased with regard to pain, fatigue, physical function and QOL $[11,12]$. In real life, the implementation of treat to target may be hampered by lack of resources and time constraints [13]. This could lead the rheumatologists to emphasise objective, standardised disease activity parameters over patients' perspectives, aspirations and personal goals. Results from this survey increase awareness on the impact of RA on patients' lives among those without the disease.

Results from this survey showed that both the physical and emotional impacts of RA on relationships are often not well understood by those without the disease. The more the patients felt understood by others, the better they can cope with the disease burden. Patients in relationships or with children felt that their disease was better understood when compared to those who are single, divorced or widowed. Important relationships with spouses or partners, children, family, friends and colleagues were generally negatively affected. Patients reported the strongest negative impacts on sex life and intimacy. Inclusion in family and social events was also negatively affected.

Regarding work ability, patients who felt the least understood from others reported greater inability to work due to fatigue, pain and unpredictability of how they feel. This is in line with the findings from a study that reported how patients with RA had to accept major adjustments in their career to maintain their jobs [14].

Patients' aspirations are primarily centred on the need for having understanding from others about the physical and emotional impact of the disease. Notably, patients underscored how RA negatively impacted the most important relationships, with 1 in 10 patients feeling that RA has ruined their life. The physical effects of RA, such as pain, stiffness and fatigue, have been reported as primary barriers to patients' daily activities. The inability to conduct these activities led to feelings of frustration and possible guilt in patients.

In line with recently published literature [15], our findings emphasise the need for identification and evaluation of outcomes that matter to patients, and that may help to achieve their personal goals. This survey also showed that lack of understanding of RA by those not affected by the disease remains a major barrier to improving patients QOL. Pitsilka et al. reported that the quality of social support that 
Table 4 Effect of RA on different aspects of patients' lives

Patients $n$ (\%) HCP $n$ (\%)

[95\% CI]

[95\% CI]

Effect of RA on relationships

How well do you think people in your/your patient's life understand the emotional

$437(35)$

$34(13)$

impact that RA has?

[32-38]

[9-17]

Patients in a relationship

$323(38)$

$29(13)$

[35-41]

[9-17]

Single, divorced or widowed patients

$114(30)$

$5(14)$

[27-33]

Patients with children

$348(38)$

$27(12)$

[35-41]

[8-16]

Patients without children

$348(28)$

$7(20)$

[25-31]

How well do you think people in your/your patient's life understand the physical impact that RA has?

$481(39)$

$55(21)$

[36-42]

[16-26]

Patients in a relationship

$350(41)$

$45(20)$

[38-44]

[15-25]

Single, divorced or widowed patients

$131(35)$

10 (28)

[32-38]

Patients with children

$382(42)$

$44(19)$

[39-45]

[14-24]

Patients without children

99 (31)

$11(31)$

[28-34] [16-46]

Which of the following aspects of your/your patient's relationships have been affected by your RA?

Your sex life and intimacy

$\begin{array}{lr}585(48) & 196(75) \\ {[45-51]} & {[70-80]}\end{array}$

Inclusion in family or social events

$541(44) \quad 176(68)$

[41-47] [62-74]

Effect of RA on work

Patients who have been forced to go on long-term leave/retire

$$
\begin{array}{r}
217(18) \\
{[16-20 \%]}
\end{array}
$$

Your/your patient's career progression seems to have slowed down since diagnosed with

$285(23)$

$165(62)$

RA

[21-25]

[56-68]

Do you feel that you/your patients receive adequate support from colleagues at work in the following areas 
Table 4 continued

\begin{tabular}{|c|c|c|}
\hline & $\begin{array}{l}\text { Patients } n(\%) \\
{[95 \% \mathrm{CI}]}\end{array}$ & $\begin{array}{l}\text { HCP } n(\%) \\
{[95 \% \mathrm{CI}]}\end{array}$ \\
\hline Accommodation and support for the physical effects of RA & $\begin{array}{l}230(31) \\
\quad[28-34]\end{array}$ & $\begin{array}{l}92(35) \\
\quad[29-41]\end{array}$ \\
\hline Accommodation and support for the emotional effects of RA & $\begin{array}{l}264(36) \\
{[33-39]}\end{array}$ & $\begin{array}{l}74(28) \\
\quad[23-33]\end{array}$ \\
\hline \multicolumn{3}{|c|}{$\begin{array}{l}\text { Aspects of having RA which provide the biggest challenges for carrying out your/your } \\
\text { patient's work? }\end{array}$} \\
\hline Difficulty using your hands & $\begin{array}{l}534(44) \\
{[41-47]}\end{array}$ & $\begin{array}{l}143(54) \\
\quad[48-60]\end{array}$ \\
\hline Inability to work due to pain & $\begin{array}{l}525(43) \\
{[40-46]}\end{array}$ & $\begin{array}{l}138(52) \\
{[46-58]}\end{array}$ \\
\hline Unpredictability of how you feel & $\begin{array}{l}408(34) \\
{[31-37]}\end{array}$ & $\begin{array}{l}72(27) \\
\quad[22-32]\end{array}$ \\
\hline
\end{tabular}

Effect of RA on activities

Which of the following activities do you/your patients consider difficult to undertake or engage in as a result of RA?

Exercising

$\begin{array}{cc}714(58) & 156(59) \\ {[55-61]} & {[53-65]} \\ 279(23) & 86(33)\end{array}$

Personal grooming

[21-25]

Which aspects of your/your patients' RA create the biggest barriers to undertaking these activities?

Pain

$745(61)$

$133(50)$

[58-64]

[44-56]

Aching/stiff joints

$632(52)$

$150(56)$

[49-55]

[50-62]

Fatigue

$451(37)$

119 (45)

[34-40]

[39-51]

How do you/your patients feel about not being able to undertake or complete these activities as a result of RA?

Frustrated

$188(71)$

[55-61]

[66-76]

Anxious

399 (32)

$127(48)$

[29-35]

[42-54]

Like a failure

309 (25)

$100(38)$

[23-27]

[32-44] 
Table 4 continued

Patients $n$ (\%) HCP $n$ (\%)

$[95 \% \mathrm{CI}]$

[95\% CI]

Effect of RA on aspirations

Looking forward, which of the statements below is most accurate to how you/your patients would like to feel about your RA?

RA hinders my life, but I accept it and do what I can

$702(57)$

[54-60]

Patients whose emotional impact was understood

Patients whose emotional impact was not understood

My RA has ruined my life and I won't ever forgive it

In the future, you/your patients wish that people in life better understand the physical

impact that RA has

How important is it to you/your patients to undertake the following without trouble?

Everyday home activities

Taking a holiday
$74(17)$

[13-21]

$40(10)$

[7-13]

$41(8)$

[6-10]

$530(43)$

[40-46]
$173(65)$

$20(59)$

[42-76]

$93(68)$

$[60-76]$

$22(8)$

[5-11]

$119(45)$

[39-51]

\begin{tabular}{lcc} 
Everyday home activities & $932(76)$ & $210(79)$ \\
& {$[74-78]$} & {$[74-84]$} \\
Taking a holiday & $848(70)$ & $173(66)$ \\
& {$[67-73]$} & {$[60-72]$} \\
\hline
\end{tabular}

$C I$ confidence interval, $H C P$ healthcare professional, $R A$ rheumatoid arthritis

patients with RA received correlated directly with their QOL, which remained statistically significantly improved irrespective of the disease severity [16].

Generally, similar observations were noted between patients and HCP responses. However, the battery of questions on disease effect on relationships and aspirations recorded the highest degree of variability between the two groups. Because of the nature of the survey, that did not include any formal statistical comparisons between the two groups and taking into account other limitations as well, we did not provide any interpretations for these findings.

The strength of this survey lies in the large sample of participants which, to our knowledge, place it among the largest surveys ever conducted on RA. However, there are major limitations too. RA Matters was designed and executed as a social media campaign. To ensure the largest possible number of participants, a mixed method sampling plan was utilized, with part of the sample coming from a panel with verified unique respondents recruited by KRC Research, and part of the sample coming from open online links that were shared by different patient advocacy groups through their social network web pages. However, including data from the online open links in the analysis would have significantly limited the reproducibility of the results. For this reason, we focused the statistical analysis on the responses coming from the verified unique respondents panel sample only. Because of such an approach, no patient response was available for the analysis in reference to three countries (Spain, Sweden, and the Netherlands). In addition, no response from the panel was available 
for HCPs from Spain. For all these reasons, the sample may not be a true representative of the overall patient population with RA. Multifactorial different participation percentage, e.g. due to higher participation from countries with more active patient advocacy groups, was not taken into account in the analyses. Cultural inter-country perspectives (ethnicity, race) related to some aspects such as relationships and work, as well as objective domains such as disease activity and duration, pain, fatigue and physical function, were not captured in the survey. In addition, socio-economic, geographical and healthcare- or work-related considerations may have influenced the answers. Finally, both the stage of disease and comorbidities were not assessed in the study and these may have an impact on the responses too.

\section{CONCLUSION}

Despite major advancements in the treatment of RA, the disease continues to significantly impact many aspects of patients' lives, including relationships, career progression, daily activities and ability to work. At the same time, both patients and HCPs feel that the physical and emotional impact of RA is not fully understood by those without the disease. Pain, stiffness and fatigue remain primary barriers and an unmet need for patients with RA. In RA treatment decisions, patients' personal goals and results of patient-reported outcomes measurement should be taken into consideration alongside clinical targets.

\section{ACKNOWLEDGEMENTS}

The authors would like to thank the patients and HCPs who participated in this survey. The authors also thank the patient associations and other members of the RA Steering Committee.

Funding. Sponsorship for this study and the Rapid Service Fee were funded by Eli Lilly and Company (Indianapolis, IN, USA).
Medical Writing and Other Assistance. Eric Roberts and Lindsay Gutekunst of KRC Research provided statistical support, sponsored by Eli Lilly and Company. Medical writing assistance in the preparation of this article was provided by Bhargav Vyasa, Ph.D., who was employed by Eli Lilly and Company at the time of the study. Bhargav Vyasa, Ph.D., is now an independent consultant.

Authorship. All named authors meet the International Committee of Medical Journal Editors (ICMJE) criteria for authorship for this article, take responsibility for the integrity of the work as a whole, and have given their approval for this version to be published.

Disclosures. Rieke Alten has received research grants and consultancy fees from Eli Lilly and Company, Pfizer and Galapagos. Mart van de Laar has received research grants from Eli Lilly and Company, Pfizer, Merck, AbbVie and Janssen Cilag, and consulting fees from Sanofi Genzyme, Eli Lilly and Company, Pfizer, Merck, AbbVie and Janssen Cilag. Francesco De Leonardis is an employee and shareholder of Eli Lilly and Company. Nicole Tietz is an employee and shareholder of Eli Lilly and Company. Mariana Guerreiro is an employee and shareholder of Eli Lilly and Company. Ronald van Vollenhoven has received research grants from BMS, GSK, Eli Lilly and Company, Pfizer and UCB, and consultancy honoraria from AbbVie, AstraZeneca, Biogen, Biotest, Celgene, GSK, Janssen, Eli Lilly and Company, Pfizer, Servier and UCB.

Compliance with Ethics Guidelines. The research was carried out in compliance with national laws protecting respondents' personal data and with the European Society for Opinion and Market Research, the European Pharmaceutical Marketing Research Association and the British Healthcare Business Intelligence Association. For this survey, ethics committee approval was not required, in line with the standards and guidelines set by Market Research Industry Associations. At the beginning of the survey, respondents were asked to explicitly 
give consent to participate in the survey. No clinical data were collected in this survey.

Data Availability. Data sharing is not applicable for this manuscript.

Open Access. This article is distributed under the terms of the Creative Commons Attribution-NonCommercial 4.0 International License (http://creativecommons.org/licenses/ by-nc/4.0/), which permits any noncommercial use, distribution, and reproduction in any medium, provided you give appropriate credit to the original author(s) and the source, provide a link to the Creative Commons license, and indicate if changes were made.

\section{REFERENCES}

1. Cojocaru M, Cojocaru IM, Silosi I, Vrabie CD, Tanasescu R. Extra-articular manifestations in rheumatoid arthritis. Maedica (Buchar). 2010;5(4):286-91.

2. Strand V, Wright GC, Bergman MJ, Tambiah J, Taylor PC. Patient expectations and perceptions of goal-setting strategies for disease management in rheumatoid arthritis. J Rheumatol. 2015;42(11):2046-54

3. O'Hara J, Rose A, Jacob I, Burke T, Walsh S, editors. An Introduction to The Burden of RA-a Socioeconomic Survey (BRASS). Birmingham: British Society of Rheumatology; 2017.

4. Carbonell J, Cobo T, Balsa A, Descalzo MA, Carmona L, SERAP Study Group. The incidence of rheumatoid arthritis in Spain: results from a nationwide primary care registry. Rheumatology (Oxford). 2008;47(7):1088-92.

5. Jean S, Hudson M, Gamache $P$, et al. Temporal trends in prevalence, incidence, and mortality for rheumatoid arthritis in Quebec, Canada: a population-based study. Clin Rheumatol. 2017;36(12):2667-71.

6. Widdifield J, Paterson JM, Bernatsky S, et al. The epidemiology of rheumatoid arthritis in Ontario, Canada. Arthritis Rheumatol. 2014;66(4):786-93.
7. Chorus AM, Miedema HS, Wevers CJ, van Der Linden S. Labour force participation among patients with rheumatoid arthritis. Ann Rheum Dis. 2000;59(7):549-54.

8. Kahlenberg JM, Fox DA. Advances in the medical treatment of rheumatoid arthritis. Hand Clin. 2011;27(1):11-20.

9. McInnes IB, Combe B, Burmester G. Understanding the patient perspective-results of the Rheumatoid Arthritis: Insights, Strategies \& Expectations (RAISE) patient needs survey. Clin Exp Rheumatol. 2013;31(3):350-7.

10. RA Matters. 2017. http://www.ramatters.eu/en_GB/ about. Accessed 12 July 2019.

11. Fautrel B, Alten R, Kirkham B, et al. Call for action: how to improve use of patient-reported outcomes to guide clinical decision making in rheumatoid arthritis. Rheumatol Int. 2018;38(6):935-47.

12. Nieuwenhuis WP, de Wit MP, Boonen A, van der Helm-van Mil AH. Changes in the clinical presentation of patients with rheumatoid arthritis from the early 1990s to the years 2010: earlier identification but more severe patient reported outcomes. Ann Rheum Dis. 2016;75(11):2054-6.

13. de Wit MP, Smolen JS, Gossec L, van der Heijde DM. Treating rheumatoid arthritis to target: the patient version of the international recommendations. Ann Rheum Dis. 2011;70(6):891-5.

14. Bertin P, Fagnani F, Duburcq A, et al. Impact of rheumatoid arthritis on career progression, productivity, and employability: the PRET Study. Jt Bone Spine. 2016;83(1):47-52.

15. Oude Voshaar MAH, Das Gupta Z, Bijlsma JWJ, et al. The International Consortium for Health Outcome Measurement (ICHOM)set of outcomes that matter to people living with inflammatory arthritis consensus from an International Working Group. Arthritis Care Res (Hoboken). 2018. https:// doi.org/10.1002/acr.23799.

16. Pitsilka DA, Kafetsios K, Niakas D. Social support and quality of life in patients with rheumatoid arthritis in Greece. Clin Exp Rheumatol. 2015;33(1):27-33. 